\title{
Concentrations of oxytocin in the intercavernous sinus of mares during luteolysis: temporal relationship with concentrations of 13,14-dihydro-15-keto-prostaglandin $F_{2 a}$
}

\author{
D. K. Vanderwall ${ }^{1 *}$, W. J. Silvia ${ }^{1 \dagger}$ and B. P. Fitzgerald ${ }^{2}$ \\ ${ }^{\mathrm{I}}$ Departments of Animal Sciences and ${ }^{2}$ Veterinary Sciences, University of Kentucky, Lexington, \\ KY 40546-0215, USA
}

\begin{abstract}
The reproductive tracts of nine thoroughbred mares were examined by ultrasound to determine the day of ovulation (day 0 ). Mares were fitted with intercavernous sinus cannulae on the day before the start of sample collection of pituitary venous effluent rich in oxytocin. Intercavernous sinus blood samples were collected for at least $36 \mathrm{~h}$ at $5 \mathrm{~min}$ intervals beginning at noon on day $13(n=2)$, day $15(n=5)$ or day $16(n=2)$ after ovulation. Concentrations of oxytocin and 13,14-dihydro-15-keto prostaglandin $F_{2 u}$ (PGFM) in plasma were determined by radioimmunoassay. Three high-magnitude surges of PGFM ( $>$ I ng ml $\mathrm{ml}^{-1}$ ) were found in these samples. Three high magnitude pulses of oxytocin ( $>200 \mathrm{pg} \mathrm{ml}^{-1}$ ) were also observed, one associated with each of the PGFM surges. In each of these cases, the oxytocin pulse appeared to follow or coincide with the onset of the PGFM surge. Lower magnitude pulses of both hormones were detected throughout the bleeding period in every mare. The average interval between these pulses was $122.3 \mathrm{~min}$ for oxytocin and $121.0 \mathrm{~min}$ for PGFM. The interval between pulses for individual mares varied from 90 to $199 \mathrm{~min}$ for oxytocin, and from 87 to $213 \mathrm{~min}$ for PGFM. However, there was no correlation between PGFM and oxytocin pulse intervals among mares. Within each mare, there was no discernable association between low magnitude pulses of oxytocin and PGFM. From these data, it was concluded that high-magnitude surges of $\mathrm{PGF}_{2 \alpha}$ are associated with similar surges of oxytocin from the posterior pituitary gland, and that $\mathrm{PGF}_{2 u}$ may induce their secretion. The posterior pituitary gland also appears to secrete oxytocin in a pulsatile manner at a frequency of approximately 1 pulse every $2 \mathrm{~h}$ but these pulses do not appear to be associated with the low magnitude pulses of $\mathrm{PGF}_{2 a}$ secreted from the uterus.
\end{abstract}

\section{Introduction}

In mares, as in other large domestic species, the uterus is required for luteal regression (Ginther and First, 1971; Stabenfeldt et al., 1974; Squires et al., 1975). It contributes to luteolysis by secreting the luteolytic hormone, prostaglandin (PG) $\mathrm{F}_{2 \alpha}$ (Sharp et al., 1989). During luteolysis, $\mathrm{PGF}_{2 \alpha}$ is secreted in a series of discrete pulses (Douglas and Ginther, 1976; Stabenfeldt et al., 1981). The endocrine factors that regulate pulsatile secretion of $\mathrm{PGF}_{2 \alpha}$ from the equine uterus are not clearly understood.

In ruminants, oxytocin appears to play an important role in this regulation (for reviews see Flint et al., 1990; Silvia et al., 1991). The acquisition of receptors for oxytocin by the endometrium appears to be a critical event in the onset of luteolysis in these species (McCracken, 1980; Stevenson et al.,

*Present address: ARBL, Colorado State University, Fort Collins, CO 80523 , USA.

${ }^{+}$Correspondence and reprint requests.

Received 7 June 1997.
1994). Oxytocin is released in pulses that coincide synchronously with pulses of $\mathrm{PGF}_{2 u^{\prime}}$. Most of this oxytocin appears to be released from the corpus luteum. Oxytocin is a potent stimulus for uterine secretion of $\mathrm{PGF}_{2 u}$. Likewise, $\mathrm{PGF}_{2 u}$ stimulates luteal secretion of oxytocin. Thus, uterine $\mathrm{PGF}_{2 u}$ and luteal oxytocin comprise a positive feedback loop. Flint et al. (1986) proposed that each synchronous episode of oxytocin and $\mathrm{PGF}_{2 \alpha}$ secretion during luteolysis occurred through the activation of this feedback loop. The precise mechanism by which the loop is activated has not been determined. McCracken et al. $(1984,1995)$ have suggested that the regular pulsatile release of oxytocin from the posterior pituitary gland may be the initiating stimulus for uterine $\mathrm{PGF}_{2 u}$ release. Pulses of luteal oxytocin during luteolysis are frequently accompanied by synchronous pulses of oxytocin from the posterior pituitary gland (Hooper et al. 1986). However, no attempt has been made to relate uterine secretion of $\mathrm{PGF}_{2 u}$ to secretion of neurohypophyseal oxytocin. The small amount of secretion and short half life make it difficult to measure neurohypophyseal oxytocin accurately in peripheral blood samples. 
Oxytocin may play a similar regulatory role in secretion of $\mathrm{PGF}_{2 u}$ from the equine uterus. Peripheral concentrations of oxytocin have been measured during the equine oestrous cycle. Burns et al. (1981) collected jugular venous samples from mares at four stages of the oestrous cycle. They found that concentrations of oxytocin were high during oestrus and 5 days after ovulation. Concentrations were lower on day 10 and day 15 after ovulation, day 15 being around the expected time of luteolysis. Tetzke et al. (1987) sampled very frequently over $8 \mathrm{~h}$ sampling periods on days $0,3,7$ and 15 after ovulation and observed a very irregular pattern of pulsatile secretion at all four stages of the oestrous cycle. In contrast to Burns et al. (1981), they found that mean concentrations of oxytocin were greatest on day 15 . Thus, the true nature of oxytocin secretion during the equine oestrous cycle remains to be determined.

The equine endometrium has receptors for oxytocin (Stull and Evans, 1986; Sharp et al, 1997). Oxytocin stimulates endometrial secretion of $\mathrm{PGF}_{2 \alpha^{\prime}}$ both in vivo (Betteridge et al., 1985; Goff et al., 1987) and in vitro (King and Evans, 1987; Franklin et al., 1989). Uterine secretion of $\mathrm{PGF}_{2 \alpha}$ can also be stimulated by manual dilation of the cervix, presumably through the reflex-induced release of oxytocin from the posterior pituitary gland (Sharp et al., 1997). However, regulation of $\mathrm{PGF}_{2 u}$ secretion in mares appears to differ from that in ruminants in at least one critical area. The equine corpus luteum is essentially devoid of oxytocin (Murray ef al., 1991; Stevenson et al., 1991). If oxytocin is playing an important role in mares, it must be secreted from an alternative site such as the posterior pituitary gland. The mare is a particularly appropriate animal model in which to study secretion of oxytocin from the posterior pituitary gland because the unique vascular anatomy of the equine head permits the relatively convenient cannulation of the intercavernous sinus (ICS) (Irvine and Alexander, 1987; Silvia et al., 1995). Venous blood draining the pituitary gland flows directly into the ICS. Blood samples collected from the ICS have much higher concentrations of many pituitary hormones (LH, FSH, ACTH and vasopressin) when compared with samples collected simultaneously from the jugular vein (Redekopp et al., 1986; Alexander and Irvine, 1987; Irvine and Alexander, 1987). Concentrations of vasopressin in the ICS can exceed those in the jugular vein by more than 500-fold (Redekopp et al., 1986). The ICS sampling procedure has been used successfully to characterize secretion of oxytocin from the posterior pituitary during parturition (Vivrette et al., 1992).

The objective of the present study was to define the characteristics of neurohypophyseal oxytocin secretion in mares and evaluate its potential role as an initiator of the luteolytic pulses of $\mathrm{PGF}_{2 \alpha}$.

\section{Materials and Methods}

\section{Animals}

Thoroughbred mares, ranging from 3 to 15 years in age and from 350 to $500 \mathrm{~kg}$ in weight, were used in these experiments. Experiments were conducted during the breeding season (May-July). The reproductive tract of each mare was examined four times per week by transrectal palpation and ultrasonography (Ginther, 1986). Once an ovarian follicle $\geq 30 \mathrm{~mm}$ in diameter was detected, mares were examined each day until ovulation. Ovulation was defined as the disappearance of an ovarian follicle $30 \mathrm{~mm}$ in diameter between two successive daily examinations, and subsequent identification of the corpus luteum by ultrasound. The day of ovulation was designated day 0 . The concentration of progesterone was quantified in jugular venous blood samples $(10 \mathrm{ml}$ ) collected by venepuncture daily on days 0-22 after ovulation to monitor luteal function, and to determine when luteolysis occurred. Plasma was collected and stored at $-20^{\circ} \mathrm{C}$ until assayed for progesterone.

The ICS of each mare was cannulated via the facial vein as described by Silvia et al. (1995). Placement of cannulae was verified by radiography at the time of insertion. Procaine penicillin-G (22 000 United States Pharmacopeia (USP) units $\mathrm{kg}^{-1}$ bodyweight) was administered i.m. at the time of cannulation and every $12 \mathrm{~h}$ thereafter for $48 \mathrm{~h}$. Sterile $0.9 \%$ saline ( $1 \mathrm{ml}$ ) containing heparin (100 USP units $\mathrm{ml}^{-1}$ ), potassium penicillin-G (100 iu $\left.\mathrm{ml}^{-1}\right)$, and streptomycin sulfate (100 $\mathrm{mg} \mathrm{ml}^{-1}$ ) was administered each hour to maintain catheter patency between cannulation and the start of sample collection. Beginning at least $6 \mathrm{~h}$ after cannulation, ICS blood samples $(5 \mathrm{ml})$ were collected every $5 \mathrm{~min}$ for up to $48 \mathrm{~h}$, depending upon the objectives of the particular experiment. Samples were collected by slow aspiration (approximately $I \mathrm{~min}$ ) using a $5 \mathrm{~cm}^{2}$ syringe so as to minimize trauma induced by severe negative pressure. Samples were transferred to a test tube containing $10 \mathrm{mg}$ EDTA and $250 \mu \mathrm{g}$ indomethacin in $0.5 \mathrm{ml}$ of water. Plasma was collected and stored at $-20^{\circ} \mathrm{C}$ until assayed for oxytocin. Uterine secretion of $\mathrm{PGF}_{2 \alpha}$ was assessed by measuring concentrations of PGFM in the same ICS blood samples. PGFM is a stable, biologically inactive, metabolite of $\mathrm{PGF}_{2 u}$ and is the first step in the clearance of $\mathrm{PGF}_{2 u}$ from the peripheral circulation (Granström and Kindahl, 1982). Peripheral concentrations of PGFM have been used by other researchers to assess uterine secretion of $\mathrm{PGF}_{2 a}$ in mares (Stabenfeldt et al., 1974, 1981; Betteridge et al., 1985; Goff et al., 1987; Vivrette et al., 1992). Immediately after collection of each sample, the cannula was slowly flushed with $8-10 \mathrm{ml}$ of the sterile saline solution described above, except that the heparin concentration was reduced to $20 \mathrm{USP}$ units $\mathrm{ml}^{-1}$. Mares were housed in box stalls throughout the sample collection period, and hay and water were provided ad libitum. At the completion of the sample collection period, cannulae placement was verified again by radiography.

\section{Preliminary experiments}

Three preliminary experiments using two mares (identification numbers 318 and 3) were conducted to validate various aspects of the ICS cannulation and sample collection procedures for quantification of oxytocin and PGFM. Preliminary Expt 1 was conducted to determine if an acute release of oxytocin could be detected by sampling from the ICS. The ICS of mare 318 was cannulated on the morning of day 12. On day 14 , the cervix of the mare was manually dilated to induce release of oxytocin. The cervix was dilated by inserting the index finger to its full length through the cervical os and gently rotating the finger for $2 \mathrm{~min}$. Blood samples were collected from the ICS at $5 \mathrm{~min}$ intervals for $2 \mathrm{~h}$ beginning $\mathrm{I} \mathrm{h}$ before cervical dilation. 
Table 1. The frequency of pulsatile oxytocin and 13,14dihydro-15-keto-prostaglandin $\mathrm{F}_{2 \alpha}$ (PGFM) secretion in individual mares during the periluteolytic period

\begin{tabular}{lcccc}
\hline & & & \multicolumn{2}{c}{ Pulses in $36 \mathrm{~h}$} \\
\cline { 4 - 5 } Mare & $\begin{array}{c}\text { Days sampled } \\
\text { (after ovulation) }\end{array}$ & $\begin{array}{c}\text { Luteolysis } \\
\text { complete }\end{array}$ & Oxytocin & PGFM \\
\hline 312 & $15-16$ & 15 & 21.5 & 22.6 \\
321 & $15-16$ & 15 & 10.8 & 24.7 \\
322 & $15-16$ & 15 & 24.0 & 19.0 \\
328 & $15-16$ & 15 & 17.0 & 20.0 \\
329 & $15-16$ & 15 & 13.9 & 17.8 \\
342 & $16-17$ & 15 & 23.2 & 19.2 \\
357 & $16-17$ & $>22$ & 23.3 & 10.1 \\
390 & $13-15$ & 18 & 22.1 & 18.5 \\
391 & $13-15$ & 17 & 14.6 & 18.8 \\
Mean & & & 18.9 & 19.0 \\
& & & &
\end{tabular}

*First day after ovulation on which progesterone $<2 \mathrm{ng} \mathrm{ml}^{-1}$.

Preliminary Expt 2 was conducted to verify that the oxytocin released in response to cervical dilation was from the posterior pituitary gland. In this experiment, the ICS of mare 3 was cannulated on the morning of day 12 . On day 16, the cervix was manually dilated for $2 \mathrm{~min}$, as in preliminary Expt 1 . Blood samples were collected from the ICS at 5 min intervals for $2 \mathrm{~h}$ beginning $1 \mathrm{~h}$ before cervical dilation. Jugular venous blood samples were drawn simultaneously through an indwelling catheter inserted immediately before the onset of sampling (Silvia et al., 1995). Concentrations of oxytocin in the ICS and jugular vein were determined by radioimmunoassay and compared.

Preliminary Expt 3 was conducted to determine if concentrations of PGFM, the stable systemic metabolite of $\mathrm{PGF}_{2 a^{\prime}}$ in ICS samples were an accurate reflection of peripheral PGFM concentrations. On day 15, mare 318 (cannulated on the morning of day 12 and used previously in preliminary Expt 1) was given an injection of oxytocin (10 iu, i.v.). ICS blood samples were collected at 5 min intervals, for $2.5 \mathrm{~h}$ beginning $30 \mathrm{~min}$ before injection. Jugular venous blood samples were drawn simultaneously through an indwelling catheter inserted immediately before the onset of sampling (Silvia et al., 1995). Concentrations of PGFM in the ICS and jugular vein were determined by radioimmunoassay and compared.

\section{Main experiment}

The ICSs of nine mares were cannulated the day before the onset of sample collection. Beginning at 12:00 h on day 13 $(n=2)$, day $15(n=5)$ or day $16(n=2)$, ICS blood samples were collected at $5 \mathrm{~min}$ intervals for $30-48 \mathrm{~h}$. Days on which sampling occurred were selected on the basis of the duration of previous oestrous cycles in an attempt to ensure that some mares were sampled during luteolysis. The days of sample collection and the time of luteolysis for each mare are presented (Table 1). Concentrations of oxytocin and PGFM were determined in the plasma by radioimmunoassay.

\section{Radioimmunoassays}

Oxytocin was quantified directly in unextracted plasma using a modification of the procedures described by Robinson (1980). Synthetic oxytocin was used as standard and iodinated using the method of Dawood et al. (1978). The principal buffer for this assay was $0.01 \mathrm{~mol} \mathrm{PBS} 1^{-1}$ with $0.01 \%(\mathrm{w} / \mathrm{v})$ thimerosal (PBS) and 0.01\% gelatin (PBS-gel). Standards (10-10 $000 \mathrm{pg}$ $\mathrm{ml}^{-1}$ ) were prepared in charcoal-extracted gelding plasma. Antiserum ( $\mathrm{R} \mathrm{III}_{5}$; a generous gift of I. C. A. F. Robinson) was diluted 1:60 000 in PBS containing 0.05 M EDTA. Standard or sample $(200 \mu \mathrm{l})$, antiserum $(200 \mu \mathrm{l})$ and tracer (approximately $30000 \mathrm{cpm}$ in $100 \mu \mathrm{l}$ PBS-gel ) were added to each tube. The final incubation volume was brought up to $800 \mu \mathrm{l}$ with PBS-gel and incubated at $4^{\circ} \mathrm{C}$ for $24 \mathrm{~h}$. Antibody-bound and free tracer were separated by second antibody precipitation at $4^{\circ} \mathrm{C}$ for $24 \mathrm{~h}$. Crossreactivity of the antiserum was $0.005 \%$ for arginine vasopressin, $0.006 \%$ for lysine vasopressin and $<0.001 \%$ for arginine vasotocin (Robinson, 1980). Serial dilutions of pooled equine plasma $(n=3)$ were parallel to the standard curve. Addition of 25,100 , and $250 \mathrm{pg}$ oxytocin to equine plasma were accurately recovered (mean recovery $=86 \%$ ). Sensitivity was defined as the concentration of oxytocin required to inhibit binding of radioiodinated oxytocin to $95 \%$ of that observed in assay tubes containing no unlabelled oxytocin $\left(B_{0}\right)$. Sensitivity of the assay averaged $11.2 \mathrm{pg} \mathrm{m} \mathrm{l}^{-1}$. Values below the assay sensitivity were assigned a value equal to the sensitivity. The intra- and interassay coefficients of variation, determined from aliquots of a plasma pool containing a concentration of oxytocin near the midpoint of the standard curve, were $9.9 \%$ and $10.0 \%$, respectively.

PGFM was quantified directly in unextracted plasma using an $\left[{ }^{3} \mathrm{H}\right] \mathrm{PGFM}$ radioimmunoassay developed in our laboratory (Homanics and Silvia, 1988). PGFM standards (50-10 000 pg $\mathrm{ml}^{-1}$ ) were prepared in charcoal-extracted gelding plasma. Serial dilutions of pooled equine plasma were parallel to the standard curve. Addition of 50, 250, and 500 pg PGFM to equine plasma were accurately recovered (mean recovery $=105 \%$ ). Sensitivity of the assay was $23.2 \mathrm{pg} \mathrm{ml}^{-1}$. Values below the assay sensitivity were assigned a value equal to the sensitivity. The intra- and interassay coefficients of variation were $10.9 \%$ and $17.0 \%$, respectively.

Progesterone was quantified directly in unextracted plasma using a solid-phase ${ }^{125}$ I-labelled progesterone radioimmunoassay kit (Coat-A-Count Progesterone; Diagnostic Products Corp., Los Angeles, CA). Progesterone standards (0.1-40 ng $\mathrm{ml}^{-1}$ ) were prepared in charcoal-extracted gelding plasma. Serial dilutions of pooled equine plasma were parallel to the standard curve. Addition of 0.1, 0.25, 0.5 and $1.0 \mathrm{ng}$ progesterone to equine plasma were accurately recovered (mean recovery $=107 \%$ ). Sensitivity of the assay was $0.09 \mathrm{ng} \mathrm{ml}^{-1}$. Values below the assay sensitivity were assigned a value equal to the sensitivity. The intra- and interassay coefficients of variation were 5.8 and $14.8 \%$, respectively.

\section{Statistical analysis}

Pulses of oxytocin and PGFM were identified using the Cluster algorithm as described by Veldhuis and Johnson (1986). Minimum peak and trough durations were set at four 


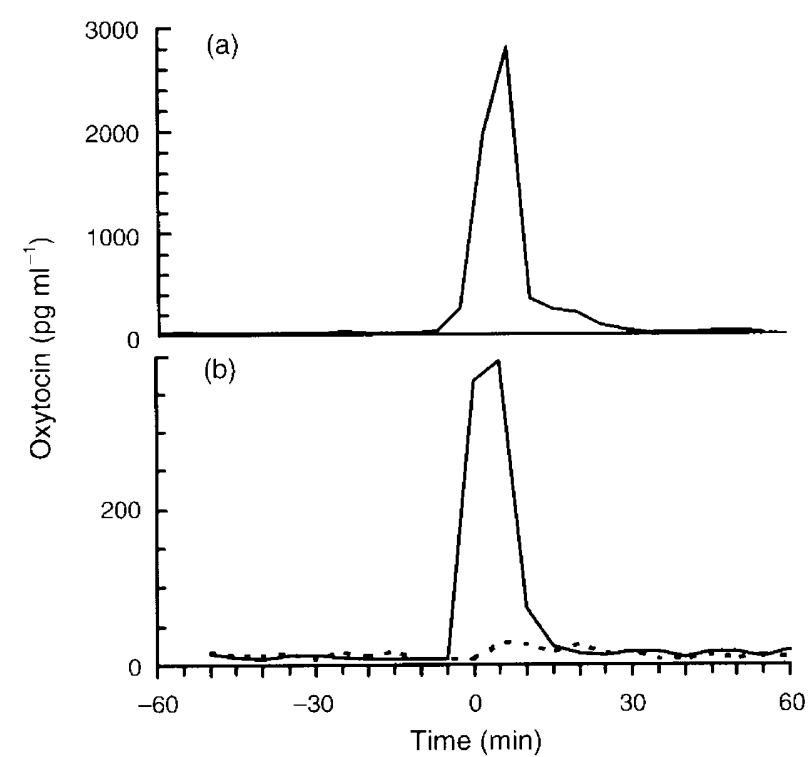

Fig. 1. Concentrations of oxytocin in intercavernous sinus $(-)$ and jugular venous (-- ) blood samples collected around the time of manual cervical dilation (dilation at time $=0$ ). Note the difference in $y$ axis scales between the two experiments. (a) Preliminary Expt I (cervical dilation 14 days after ovulation). (b) Preliminary Expt 2 (cervical dilation 16 days after ovulation).

consecutive samples. This corresponds to durations of $20 \mathrm{~min}$ at the $5 \mathrm{~min}$ sampling frequency used. The mean number of pulses detected in $36 \mathrm{~h}$ was calculated. The presence of regular

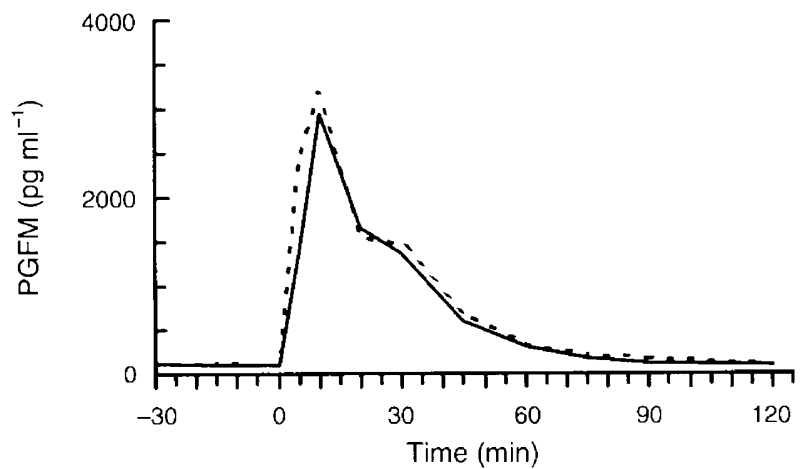

Fig. 2. Concentrations of 13,14-dihydro-15-keto prostaglandin $F_{2 u}$ (PGFM) in intercavernous sinus $(\longrightarrow$ and jugular venous $(---)$ blood samples collected around the time of intravenous injection of oxytocin (injection at time $=0$ ) in preliminary Expt 3. Oxytocin administered 15 days after ovulation.

rhythms in oxytocin or PGFM with periods ranging from 10 min to $16.5 \mathrm{~h}$ were determined for each mare using the ARIMA procedures of SAS (1985). Considering the relatively short bleeding time (about $36 \mathrm{~h}$ ), rhythms with longer periods could not be identified.

Luteolysis was judged to be completed if peripheral concentrations of progesterone had decreased to $<2 \mathrm{ng} \mathrm{ml}^{-1}$. While this is higher than the I $\mathrm{ng} \mathrm{ml}^{-1}$ used conventionally, it was chosen as a reference point because it was closer to the time of active luteolysis. In our experience, once a fully functional corpus luteum is formed (by day 8 after ovulation)

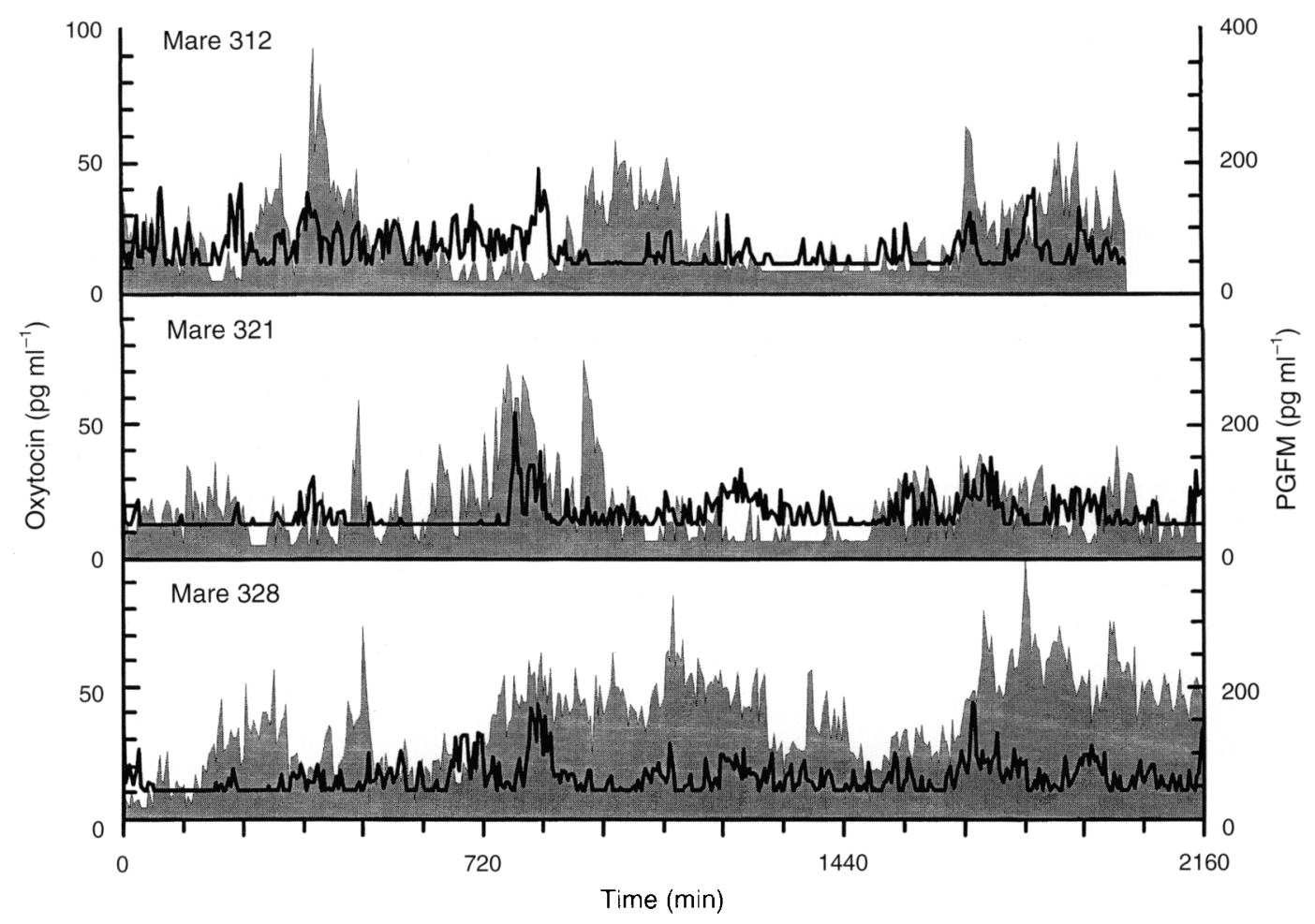

Fig. 3. Concentrations of oxytocin (- - ) and 13,14-dihydro-15-keto prostaglandin $F_{2 " 1}$ (PGFM) (shaded area) over the $36 \mathrm{~h}$ sampling period in three mares (mare numbers 312,321 and 328). Sampling began at $12: 00 \mathrm{~h}$ on day 15 after ovulation for all three mares. 


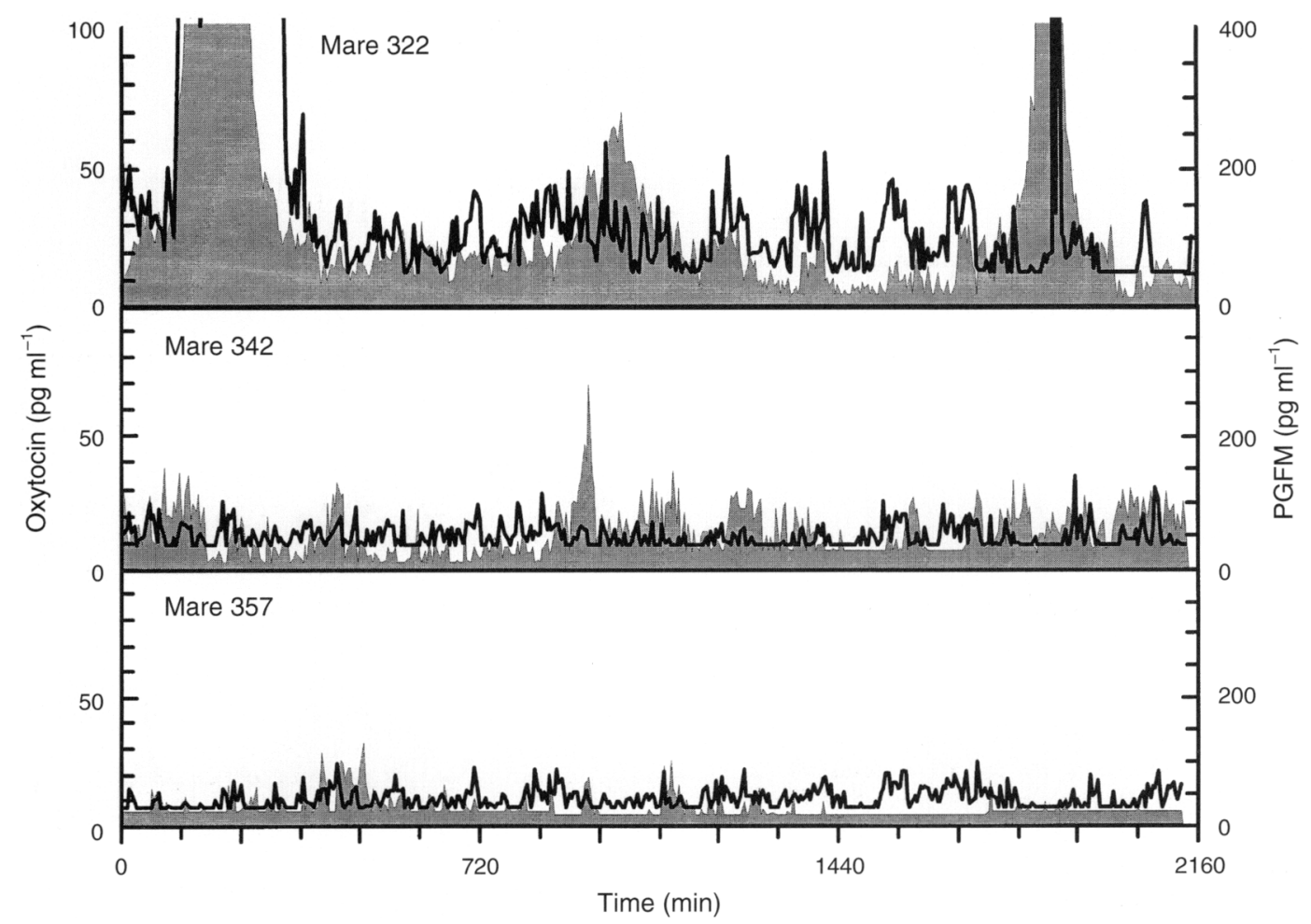

Fig. 4. Concentrations of oxytocin ( $\longrightarrow$ ) and 13,14-dihydro-15-keto prostaglandin $F_{2 u}$ (PGFM) (shaded area) over the $36 \mathrm{~h}$ sampling period in three mares (mare numbers 322, 342 and 357). Sampling began at 12:00 h on day 15 after ovulation for mare 322 , and at $12: 00 \mathrm{~h}$ on day 16 for mares 342 and 357.

progesterone concentrations do not fall below $2 \mathrm{ng} \mathrm{ml}^{-1}$ until luteolysis is irreversibly underway. The effect of time of sampling relative to luteolysis (that is, samples collected before versus after completion of luteolysis) on numbers of pulses in $36 \mathrm{~h}$ was determined by Student's $t$ test.

\section{Results}

\section{Preliminary experiments}

Concentrations of oxytocin increased in ICS samples collected after manual cervical dilation (preliminary Expt I; Fig. Ia). Concentrations reached a maximum $10 \mathrm{~min}$ after dilation and decreased to basal concentrations by $30 \mathrm{~min}$. A similar response was observed after cervical dilation in another mare (preliminary Expt 2; Fig. 1b). A small simultaneous increase in oxytocin was also detected in the jugular vein but was only $1 / 8$ in magnitude of the increase observed in the ICS samples, indicating that the oxytocin released during cervical stimulation was most likely from the posterior pituitary gland. Concentrations of PGFM increased immediately after injection of oxytocin on day 16 after ovulation (preliminary Expt 3; Fig. 2). The increase was similar in timing and in magnitude in both jugular venous and in ICS samples. Therefore, ICS samples can be used to determine peripheral PGFM concentrations accurately.

\section{Main experiment}

The patterns of oxytocin and PGFM in ICS samples for up to $36 \mathrm{~h}$ from all nine mares are presented (Figs 3-5). Oxytocin was clearly secreted in a pulsatile manner. The vast majority of these pulses were of relatively small magnitude and were secreted at an average frequency of approximately 1 pulse every $122.3 \mathrm{~min}$ (Table 1 ). These pulses can be seen in more detail in representative, $12 \mathrm{~h}$ bleeding windows from six mares (Figs 6 and 7). Concentrations of PGFM also showed a pulsatile pattern of secretion (Figs 3-7), with small magnitude pulses detected at a similar frequency to that observed for oxytocin ( 1 pulse every 121.0 min; Table 1 ). The interval between pulses for individual mares varied from 90 to $199 \mathrm{~min}$ for oxytocin and from 87 to 213 min for PGFM. There was no correlation between PGFM and oxytocin pulse intervals among mares. There was no discernable temporal association of low magnitude oxytocin and PGFM pulses in any of the mares (Figs 6 and 7).

Three very high magnitude surges $\left(>200 \mathrm{pg} \mathrm{ml}^{-1}\right)$ of oxytocin were detected in two mares (mare numbers 322, 329; Fig. 8). Each of these was associated with a high magnitude pulse of PGFM ( $>1000 \mathrm{pg} \mathrm{ml}^{-1}$ ). In each case, the increase in PGFM appeared to precede or coincide with the increase in oxytocin. The magnitude of the PGFM surges was extremely consistent at almost $2000 \mathrm{pg} \mathrm{ml}^{-1}$. However, the magnitudes of the concomitant oxytocin pulses were extremely variable, ranging from just over $100 \mathrm{pg} \mathrm{ml}^{-1}$ (the second pulse in mare 329 ) to $>5000 \mathrm{pg} \mathrm{ml}^{-1}$ (the first pulse in mare 329).

Mares could be classified into two groups according to the time of sampling relative to luteolysis (Table 1). Six mares (312, $321,322,328,329,342$ ) were sampled after luteolysis was complete. The two mares exhibiting greater magnitude 


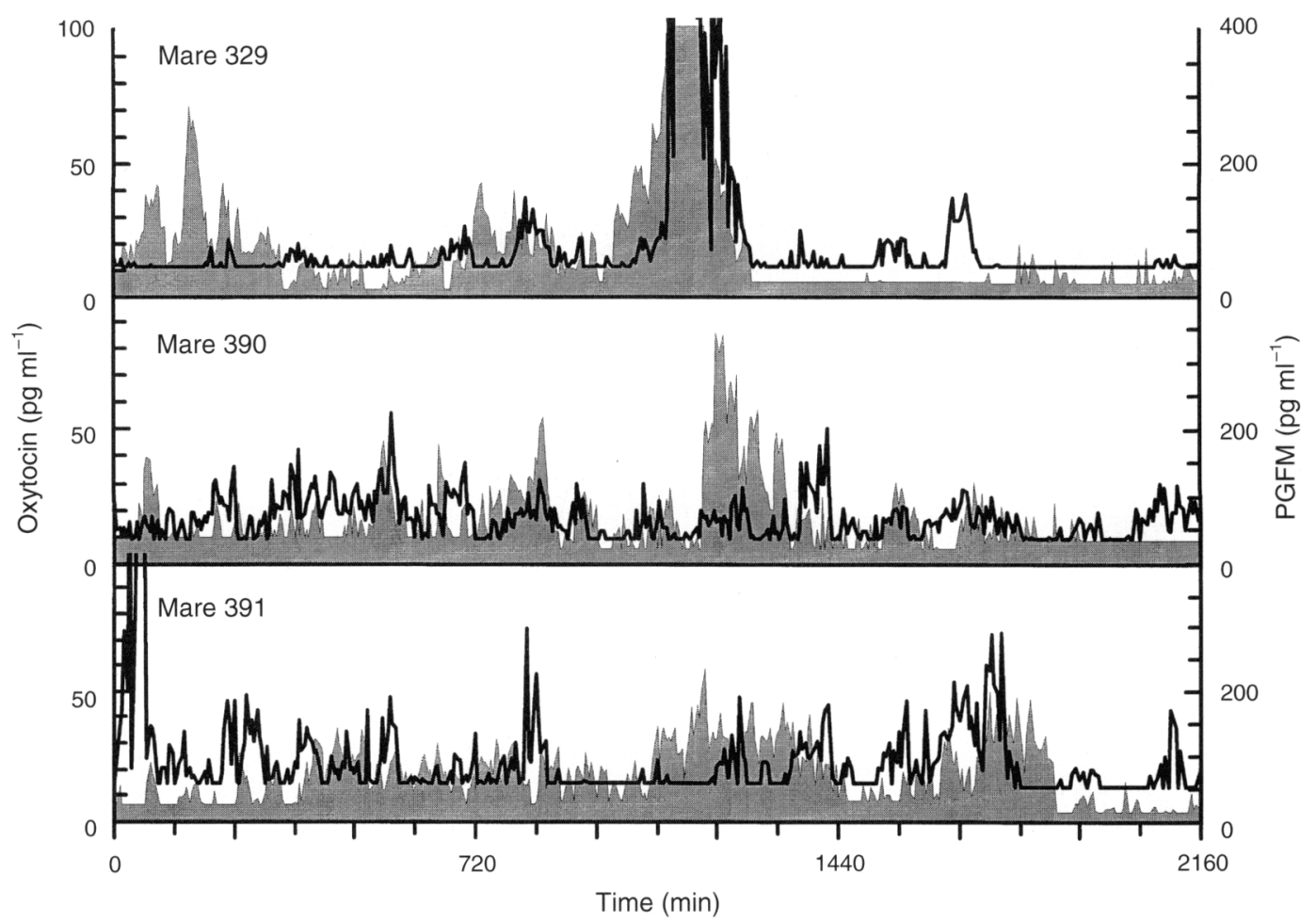

Fig. 5. Concentrations of oxytocin ( $\longrightarrow$ ) and 13,14-dihydro-15-keto prostaglandin $F_{211}$ (PGFM) (shaded area) over the $36 \mathrm{~h}$ sampling period in three mares (mare numbers 329, 390 and 391). Sampling began at 12:00 h on day 15 after ovulation for mare 329, and at 12:00 h on day 13 for mares 390 and 391 .

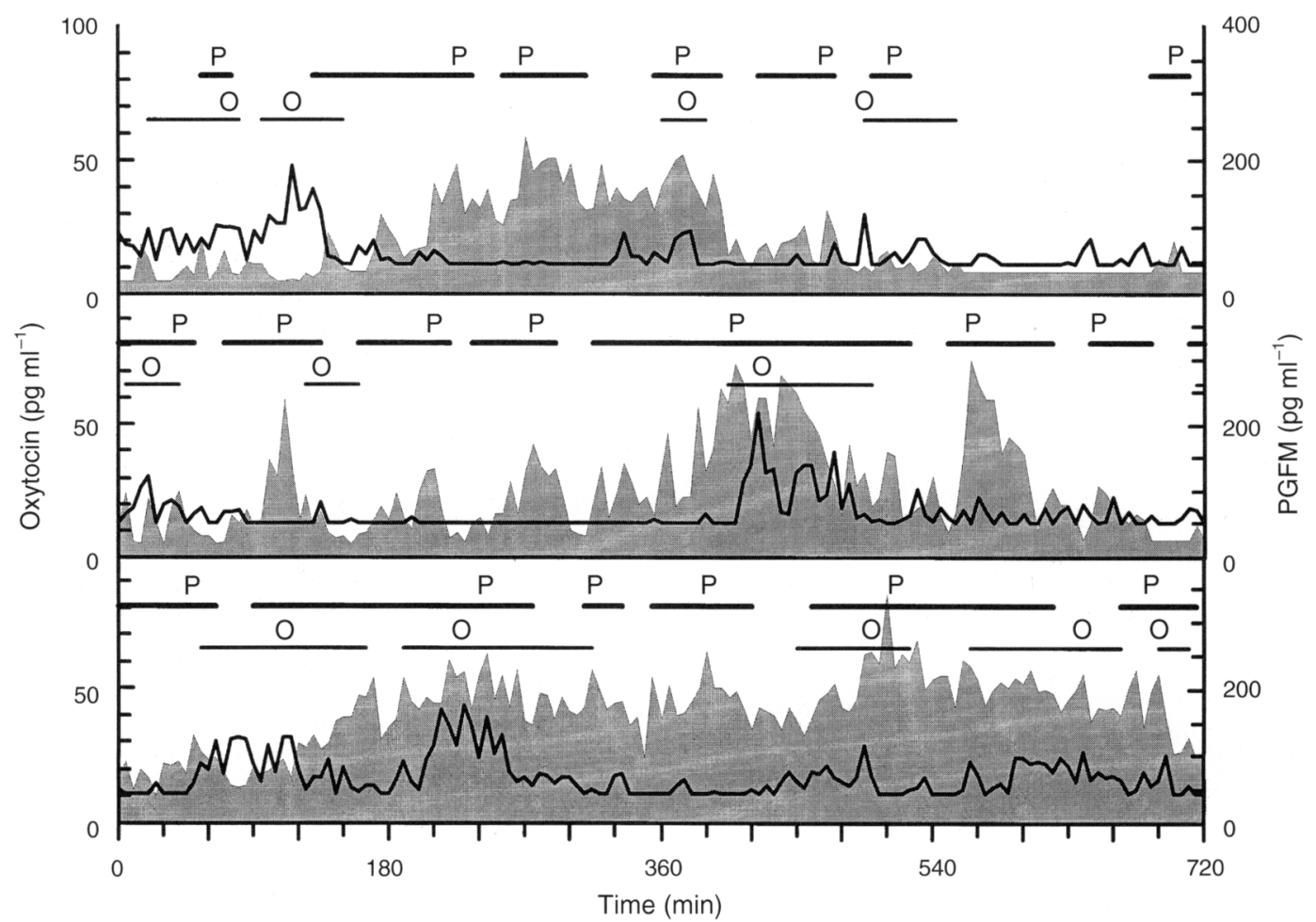

Fig. 6. Concentrations of oxytocin ( $\longrightarrow$ ) and 13,14-dihydro-15-keto prostaglandin $F_{2 u}$ (PGFM) (shaded area) over a $12 \mathrm{~h}$ period in three mares (top panel: mare number 312 , corresponding to $720-1440 \mathrm{~min}$ in Fig. 3; middle panel: mare number 321 , corresponding to $360-1080 \mathrm{~min}$ in Fig. 3; bottom panel: mare number 328, corresponding to 600-1320 min in Fig. 3). Horizontal bars across the upper portion of each panel indicate samples that contribute to a pulse series identified by cluster analysis (O, oxytocin; $P$, PGFM). The highest value within each series is identified by the letter that sits directly above the horizontal line. 


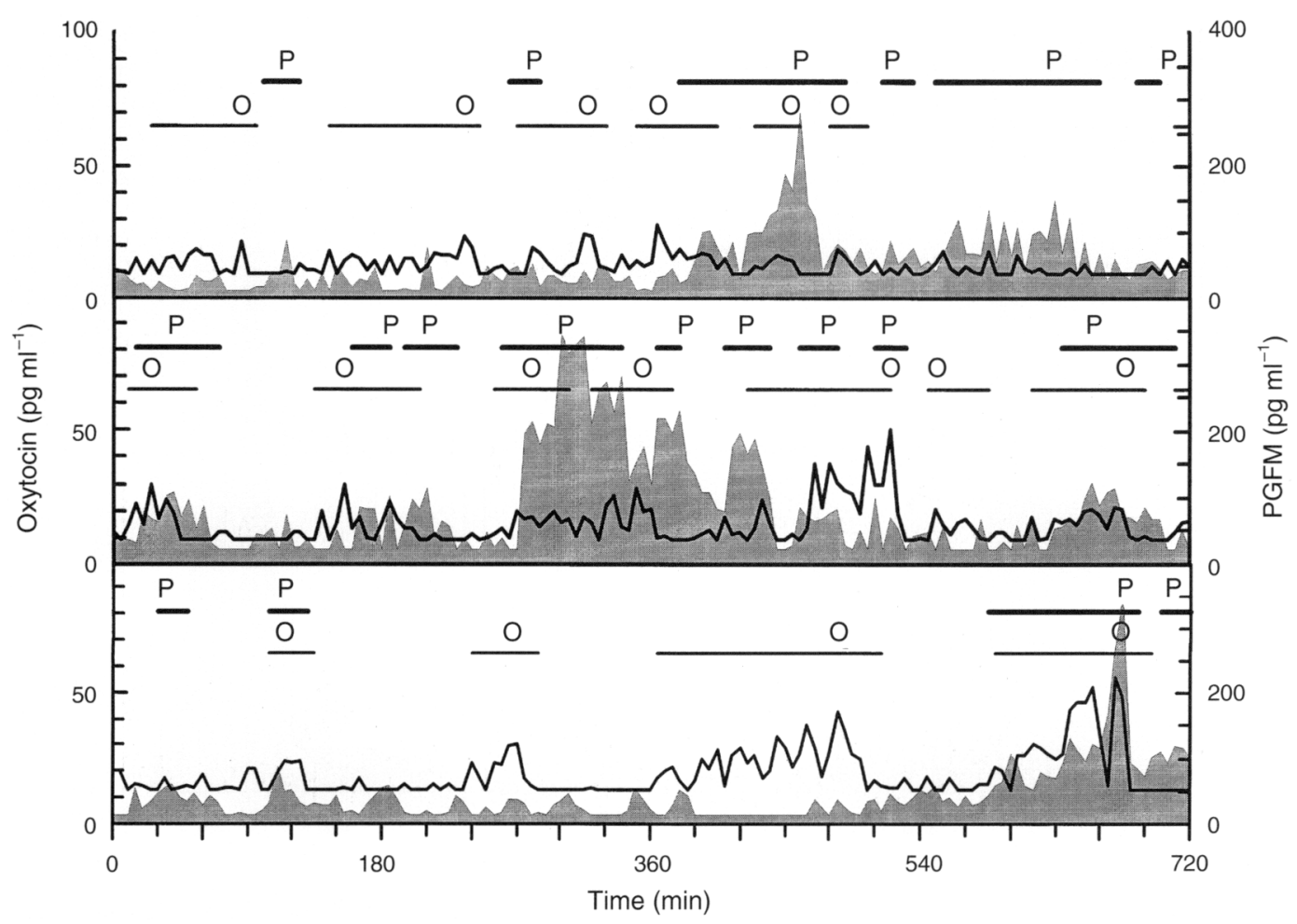

Fig. 7. Concentrations of oxytocin (-) and 13,14-dihydro-15-keto prostaglandin $\mathrm{F}_{2 u}$ (PGFM) (shaded area) over a $12 \mathrm{~h}$ period in three mares (top panel: mare number 342 , corresponding to $480-1200 \mathrm{~min}$ in Fig. 4; middle panel: mare number 390, corresponding to $900-1620 \mathrm{~min}$ in Fig. 5; bottom panel: mare number 391, corresponding to 2160-2880 min that do not appear in Fig. 5). Horizontal bars across the upper portion of each panel indicate samples that contribute to a pulse series identified by cluster analysis $(O$, oxytocin; $P$, PGFM). The highest value within each series is identified by the letter that sits directly above the horizontal line.

(luteolytic) pulses of PGFM and oxytocin were from this group. Three mares $(357,390,391)$ were sampled before the onset of luteolysis. The pulsatile pattern of oxytocin or PGFM did not appear to be affected by the time of sampling relative to luteolysis. No significant rhythms with frequencies ranging from $5 \mathrm{~min}$ to $16.5 \mathrm{~h}$ were detected for either hormone. On the basis of simple visual examination of the data, there was no evidence of rhythms with longer periods for either hormone.

\section{Discussion}

From the preliminary experiments, it is clear that manual cervical dilation induces a prompt release of oxytocin. Sharp ef al. (1997) have observed a much smaller increase in peripheral concentrations of oxytocin after transcervical uterine biopsy. In preliminary Expt 2, concentrations in samples collected from the ICS were compared with those collected from the jugular vein. The eightfold higher concentrations observed in the ICS versus the jugular vein strongly support the hypothesis that this oxytocin is of neurohypophyseal origin. Taken together, these data confirm the existence of a 'Ferguson reflex' as proposed by Sharp et al. (1997). The magnitude of the response was much greater in mare 312 than in mare 3 . This may reflect a higher sensitivity of the reflex system on day 14 versus that on day 16 after ovulation. Sharp et al. (1997) showed that the release of oxytocin in response to transcervical uterine biopsy changes over the course of the oestrous cycle.

Oxytocin appears to be secreted in a series of irregularly timed 'pulses' during the periluteolytic period. This pattern is similar to the one described by Tetzke et al. (1987) for samples collected from the jugular vein. The origin of these low magnitude pulses cannot be determined because simultaneous ICS and peripheral samples were not collected in this study. The basal pattern of release is somewhat similar to the pattern of vasopressin in mares sampled from the ICS (Redekopp et al., 1986). While these pulses are most likely secreted from the posterior pituitary, other sources of oxytocin such as the uterus cannot be ruled out (Behrendt et al., 1997). Thus, the ICScannulated mare appears to be an appropriate animal model in which to study the pattern of oxytocin secretion and acute aspects of its regulation. It should be recognized that slight differences in cannula placement can influence absolute concentrations of oxytocin in samples obtained from the ICS. Data should be interpreted with this concern in mind. Even in the ICS, pulses of both oxytocin and vasopressin are much less clearly defined than gonadotrophin pulses (Alexander and Irvine, 1987; Irvine and Alexander, 1987; Silvia et al., 1995) and may reflect fundamental differences in control of neuropeptide versus gonadotrophin secretion. 


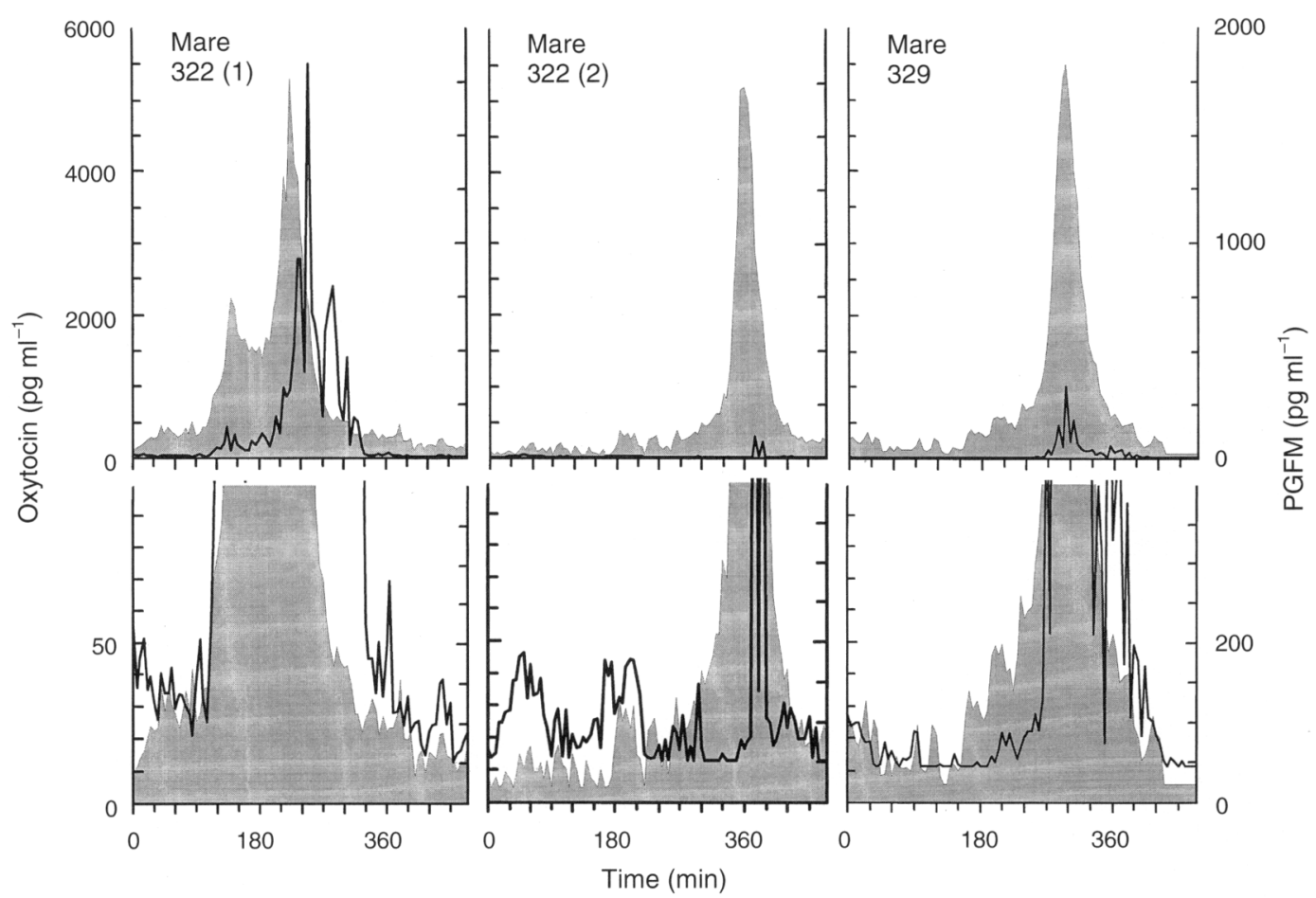

Fig. 8. Concentrations of oxytocin (-) and 13,14-dihydro-15-keto prostaglandin $\mathrm{F}_{2 u}$ (PGFM) (shaded area) over an $8 \mathrm{~h}$ period in mares during three high magnitude (luteolytic) pulses. Upper panel of each pair is shown at an expanded scale to give an accurate presentation of pulse magnitude. The lower panel of each pair is shown in a reduced scale so that the small fluctuation preceding each pulse can be visualized.

While it can be difficult to establish causative relationships between secreted hormones because of lag time in responses and differences in clearance rates, there appears to be no relationship between the low magnitude pulses of oxytocin and PGFM detected in these mares. However, this interpretation must be made with some reservation. Even though blood samples were collected from the ICS, many samples had concentrations of oxytocin at or below the sensitivity of the radioimmunoassay. Therefore, the basal concentration of oxytocin from which pulses were identified was very low, with little or no variance. Under these circumstances, very small 'episodes' of oxytocin release are easily identified and may represent an overestimate of true pulsatile secretory activity. It should also be noted that when the true baseline is below the sensitivity of the assay, it is impossible to determine the true onset and completion of individual pulses.

The failure to detect high-magnitude pulses of PGFM in more of the mares in the present study is hard to explain. As in other large domestic species, PGFM pulses typically occur immediately before, and for $24-48 \mathrm{~h}$ after, luteolysis in mares (Neely et al., 1979). On the basis of the timing of luteolysis (Table 1), high-magnitude pulses of PGFM would be expected in four other mares $(312,321,329$ and 342) in addition to those in which pulses were observed. It is not surprising that we did not detect high-magnitude pulses of PGFM in mares 390 and 391 since these mares were sampled several days before luteolysis. It is possible that, in the process of sample collection, enough oxytocin was removed from the system to delay the normal luteolytic process in these two mares. However, this seems extremely unlikely since blood flow through the ICS is approximately $25 \mathrm{ml} \mathrm{min}^{-1}$ (Irvine and Alexander, 1987) and we are removing only about $1 \mathrm{ml} \mathrm{min}{ }^{-1}$ in the course of collecting samples. Mare 357 appears to be an unusual case of abnormally prolonged luteal function.

Although limited in number, the marked association of high-magnitude surges of oxytocin and PGFM indicates clearly that the release of these two hormones is related. However, there does not appear to be an increase in oxytocin secretion preceding these surges of PGFM. A similar temporal association between PGFM and oxytocin was observed in pregnant mares at parturition (Vivrette et al., 1992). The variability in the magnitude of the oxytocin pulses associated with each surge of PGFM was remarkable. It is possible that this is an accurate reflection of the variability in oxytocin release from the posterior pituitary. As noted above, the responsiveness of the posterior pituitary to physical stimuli changes throughout the oestrous cycle. Similar changes in responsiveness to endocrine stimuli may occur as well. It is also possible that results reflect variation in the placement of the cannula and subsequent dilution of pituitary venous effluent.

Contrary to the model proposed for ewes by McCracken et al. (1984), the data presented here suggest that the increase in uterine secretion of $\mathrm{PGF}_{2 u}$ (as indicated by an increase in peripheral concentrations of PGFM) may be the trigger for the secretion of oxytocin from the posterior pituitary gland in mares. In an experiment using a single mare, an intramuscular injection of $\mathrm{PGF}_{2 u}$ stimulated a prompt release of oxytocin from the posterior pituitary gland (D. K. Vanderwall and 
W. J. Silvia, unpublished). In this respect, the posterior pituitary gland appears to serve a similar role to the corpus luteum in ruminants by providing oxytocin during luteolytic surges. Thus, the posterior pituitary gland may contribute to a positive feedback loop that amplifies pulses of $\mathrm{PGF}_{2 v}$ once they are initiated but it does not appear to be a stimulus for the initiation of these pulses. Such a system may be possible in mares, in which uterine $\mathrm{PGF}_{2 a}$ reaches the corpus luteum through a systemic route as opposed to the local, countercurrent transfer system believed to be present in ruminants (McCracken et al., 1972; Ginther, 1974). Puimonary metabolism of PGF $_{2 a}$ must be much less efficient in mares than in ruminants for a systemic utero-luteal pathway to be effective. This may make it possible for uterine $\mathrm{PGF}_{2 \alpha}$ to reach the posterior pituitary gland in sufficient quantities to stimulate oxytocin secretion.

This research was supported by the Kentucky Agricultural Experiment Station and published with the approval of the Director (Publication No. 96-07-183). The authors thank S. Vivrette (North Carolina State University) for her invaluable assistance with the ICS catheterization technique, and establishment of the oxytocin radioimmunoassay in our laboratory; I. C. A. F. Robinson (National Institute for Medical Research, London) for generous donation of the oxytocin antiserum; and B. Curd, S. Hayes, C. Holman, J. Light, J. Osten, R. Swope, and A. Willoughby for excellent technical assistance. Finally, the authors would like to thank the two anonymous referees whose constructive criticism made a significant contribution to the quality of this manuscript.

\section{References}

Alexander SL and Irvine CHG (1987) Secretion rates and short-term patterns of gonadotropin-releasing hormone, $\mathrm{FSH}$ and $\mathrm{LH}$ throughout the periovulatory period in the mare Journal of Endocrinology 114 351-362

Behrendt CY, Adams MH, Daniel KS and McDowell KJ (1997) Oxytocin expression by equine endometrium Biology of Reproduction 56 (Supplement 1) 134

Betteridge KJ, Renard A and Goff AK (1985) Uterine prostaglandin release relative to embryo collection, transfer procedures and maintenance of the corpus luteum Equine Veterinary Journal (Supplement 3) 25-33

Burns PJ, Kumaresan P and Douglas RH (1981) Plasma oxytocin concentrations in cyclic mares and sexually aroused stallions Theriogenology 16 531-539

Dawood MY, Raghavan KS, and Pociask C (1978) Radioimmunoassay of oxytocin Journal of Endocrinology 76 261-270

Douglas RH and Ginther OJ (1976) Concentrations of prostaglandin F in uterine venous plasma of anesthetized mares during the estrous cycle and early pregnancy Prostaglandins 11. 251-260

Flint APF, Sheldrick EL, Theodosis DT and Wooding FBP (1986) Ovarian peptides: role of luteal oxytocin in the control of estrous cyclicity in ruminants Journal of Animal Science 62 (Supplement 2) 62-71

Flint APF, Sheldrick EL, McCann TJ and Jones DSC (1990) Luteal oxytocin: characteristics and control of synchronous episodes of oxytocin and $\mathrm{PGF}_{2 u}$ secretion at luteolysis in ruminants Domestic Animal Endocrinology 7 111-124

Franklin KJ, Gross TS, Dubois DH and Sharp DC (1989) In vitro prostaglandin secretion from luminal and myometrial sides of endometrium from cyclic and pregnant mares at day 14 postestrus Biology of Reproduction $\mathbf{4 0}$ (Supplement 1) Abstract 114

Ginther OJ (1974) Internal regulation of physiological processes through venoarterial pathways: a review Journal of Animal Science 39 550-564

Ginther OJ (1986) Ultrasonic Imaging and Reproductive Events in the Mare pp 133-169 Equiservices, Cross Plains, W]

Ginther OJ and First NL (1971) Maintenance of the corpus luteum in hysterectomized mares American Journal of Veterinary Research 32 1687-1691
Goff AK, Pontbriand D and Sirois J (1987) Oxytocin stimulation of plasma 15-keto-13, 14-dihydro-prostaglandin $\mathrm{F}_{2 a}$ during the oestrous cycle and early pregnancy in the mare Journal of Reproduction and Fertility Supplement 35 253-260

Granström E and Kindahl H (1982) Species differences in circulating prostaglandin metabolites: relevance for the assay of prostaglandin release Biochimica ef Biophysica Acta 713 555-569

Homanics GE and Silvia WJ (1988) Effects of progesterone and estradiol-17ß on uterine secretion of prostaglandin $\mathrm{F}_{2 u}$ in response to oxytocin in ovariectomized ewes Biology of Reproduction 38 804-811

Hooper SB, Watkins WB and Thorburn GD (1986) Oxytocin, oxytocinassociated neurophysin, and prostaglandin $F_{2 u}$ concentrations in the utero-ovarian vein of pregnant and nonpregnant sheep Endocrinology 119 2590-2597

Irvine CHG and Alexander SL (1987) A novel technique for measuring hypothalamic and pituitary hormone secretion rates from collection of pituitary venous effluent in the normal horse Journal of Endocrinology 113 183-192

King SS and Evans JW (1987) Effects of arachidonic acid and oxytocin on equine endometrial PGF $_{2 k}$ during normal estrous cycles and pseudopregnancy Journal of Equine Veterinary Science 7 303-308

McCracken JA (1980) Hormone receptor control of prostaglandin $\mathrm{F}_{2 a}$ secretion by the ovine uterus Advances in Prostaglandin and Thromboxane Research $\mathbf{8}$ 1329-1344

McCracken JA, Carlson JC, Glew ME, Goding JR, Baird DT, Green K and Samuelsson B (1972) Prostaglandin F2 identified as a luteolytic hormone in sheep Nature (New Biology) 238 129-134

McCracken JA, Schramm W and Okulicz WC (1984) Hormone receptor control of pulsatile secretion of $\mathrm{PGF}_{2 u}$ from the ovine uterus during luteolysis and its abrogation in early pregnancy Animal Reproduction Science 7 31-55

McCracken JA, Custer EE, Lamsa JC and Robinson AG (1995) The central oxytocin pulse generator: a pacemaker for luteolysis. In Oxytocin pp 133-154 Eds R Ivell and J Russell. Plenum Press, New York

Murray MA, Evans JW, Dees WL and Forrest DW (1991) Immunocytochemical localization of oxytocin in the equine corpus luteum Proceedings of the Equine Nutrition and Physiology Sympositum 12 185-186

Neely DP, Kindahl H, Stabenfeldt GH, Edqvist L and Hughes JP (1979) Prostaglandin release patterns in the mare: physiological, pathophysiological and therapeutic responses Journal of Reproduction and Fertility Supplement 27 181-189

Redekopp C, Irvine CHG, Donald RA, Livesey JH, Sadler W, Nicholls MG, Alexander SL and Evans MJ (1986) Spontaneous and stimulated adrenocorticotropin and vasopressin pulsatile secretion in the pituitary venous effluent of the horse Endocrinology 118 1410-1416

Robinson ICAF (1980) The development and evaluation of a sensitive and specific radioimmunoassay for oxytocin in unextracted plasma Journal of Immunoassay $1323-347$

SAS (1985) SAS User's Guide Statistical Analysis System Institute Inc., Cary, NC

Sharp DC, McDowell KJ, Weithenauer J and Thatcher WW (1989) The continuum of events leading to maternal recognition of pregnancy in mares Journal of Reproduction and Fertility Supplement 37 101-107

Sharp DC, Thatcher MJ, Salute ME and Fuchs AR (1997) Relationship between oxytocin receptors and oxytocin-induced prostaglandin $\mathrm{F}_{2 \pi t}$ release during the oestrous cycle and early pregnancy in pony mares Journal of Reproduction and Fertility 109 137-144

Silvia WJ, Lewis GS, McCracken JA, Thatcher WW and Wilson L, Jr (1991) Hormonal regulation of uterine secretion of prostaglandin $\mathrm{F}_{2 u}$ during luteolysis in ruminants Biology of Reproduction 45 655-663

Silvia PJ, Meyer SL and Fitzgerald BP (1995) Pulsatile gonadotropin secretion determined by frequent sampling from the intercavernous sinus of the mare: possible modulatory role of progesterone during luteolysis Biology of Reproduction 53 438-446

Squires EL, Wentworth BC and Ginther OJ (1975) Progesterone concentration in blood of mares during the estrous cycle, pregnancy and after hysterectomy Journal of Animal Science 39 759-767

Stabenfeldt GH, Hughes JP, Wheat JD, Evans JW, Kennedy PC and Cupps PT (1974) The role of the uterus in ovarian control in the mare Journal of Reproduction and Fertility $37343-351$

Stabenfeldt GH, Kindahl H, Hughes JP, Neely DP, Lin I and Pascoe (1981) Control of luteolysis in the mare Acta Veterinarica Scandinavica (Supplement 77) $159-170$ 
Stevenson KR, Parkinson TJ and Wathes DC (1991) Measurement of oxytocin concentrations in plasma and ovarian extracts during the oestrous cycle of mares Journal of Reproduction and Fertility 93 437-441

Stevenson KR, Riley PR, Stewart HJ, Flint APF and Wathes DC (1994) Localization of oxytocin receptor mRNA in the ovine uterus during the oestrous cycle and early pregnancy Journal of Molecular Endocrinology 12 93-105

Stull $\mathrm{CL}$ and Evans JW (1986) Oxytocin binding in the uterus of the cycling mare Journal of Equine Veferinary Science 6 114-119
Tetzke TA, Ismail S, Mikuckis G and Evans JW (1987) Patterns of oxytocin secretion during the oestrous cycle of the mare Journal of Reproduction and Fertility Supplement 35 245-252

Veldhuis JD and Johnson ML (1986) Cluster analysis: a simple, versatile, and robust algorithm for endocrine pulse detection American Journal of Physiology 250 E486-E493

Vivrette SH, Kindahl H, Munroe C and Stabenfeldt G (1992) The initiation of parturition in the mare: prostaglandin $\mathrm{F}_{2 u}$ or oxytocin Biology of Reproduction 46 (Supplement 1) Abstract 178 